\title{
Leave a Legacy
}

Vishrut Jain

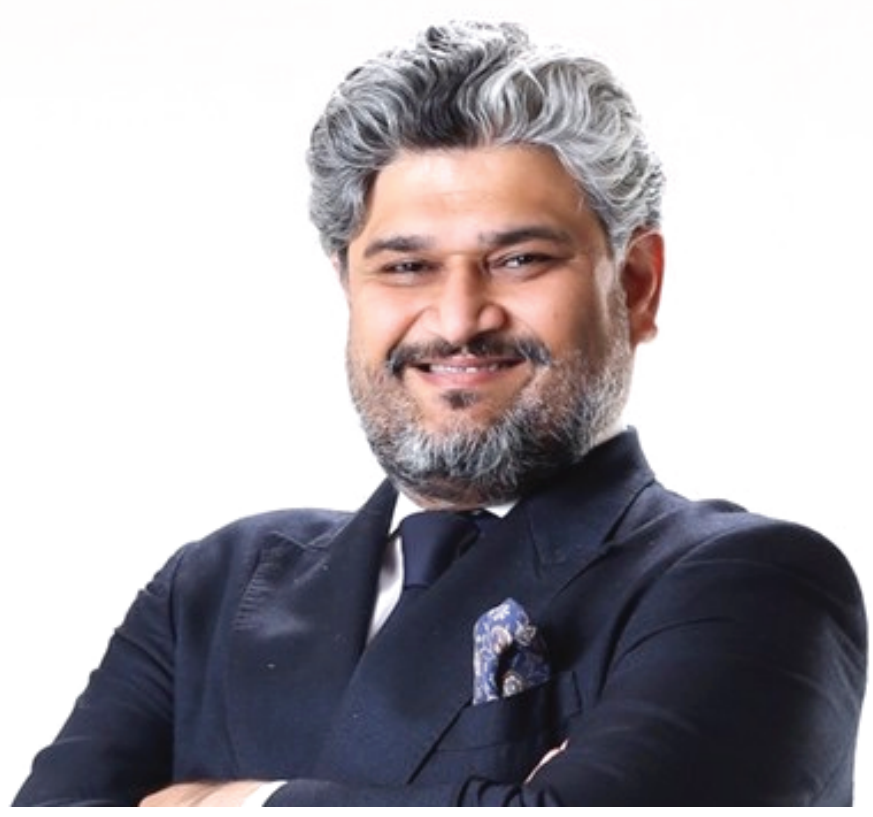

Graduating with first class honors, Vishrut Jain embarked on a career in consulting, financial services, arts and digital transformation. During a hike in Nepal with his wife Priya, he realized that the 8-year old girl hand washing sheets in cold water was a little slave girl sold for $\mathbf{\$ 1 3 0}$. He co-founded 'Kanya', a charity that adopted 18 extremely poor girls and ensured holistic nutrition, healthcare and education for them. Vishrut lived for 44 years but effortlessly packed another 44 years in accomplishments and impact. 


\section{Growing Up}

Carve your name on hearts, not tombstones. These words by Shannon Adler aptly sum up the story of Vishrut Jain - a doting family man, successful professional, collector, epicure, and philanthropist. Vishrut had a loving childhood in Lucknow surrounded by role models at home and school. His father is a doctor and his mother a teacher and home maker. He has a sister 7 years younger and they were the pride and joy of their parents. His key influences growing up were his grandfather, father, uncle, and Jagdish Gandhi, the founder of City Montessori School (CMS) Lucknow. Vishrut's grandfather donated all his savings to charity and the family's early days were humble but happy, starting in a refugee colony followed by Balrampur Hospital Campus residences in the city.

He was adventurous and fearless from a young age, walking to school on his own when he was five and shopping for groceries when he was six. Vishrut's hobbies were reading and painting and some of his works are in Lalit Kala Academy's permanent collection. His academic and extra-curricular talents blossomed at CMS. He excelled in debates, singing competitions and was appointed Head Boy in both the junior and senior sections. Vishrut also trained in martial arts and had a Taekwondo black belt by the time he finished his school.

He qualified for the highly competitive National Talent Search scholarship and for the National Residential School scholarship, the latter a ticket to Delhi Public School, RK Puram. The process of qualifying for the National Residential Scholarship was not without its challenges. The competition was open to Class 7 and 8 students and since he was still in Class 7, his 
teachers actively discouraged him from taking the exam saying that he wouldn't stand a chance against older students.

This was a defining moment and laid the foundation for his lifelong confidence. Encouraged by his father, he took the exam and stood ninth in the country. However, he chose to stay on at CMS due to its emphasis on a holistic education imbued with moral values and respect for diversity.

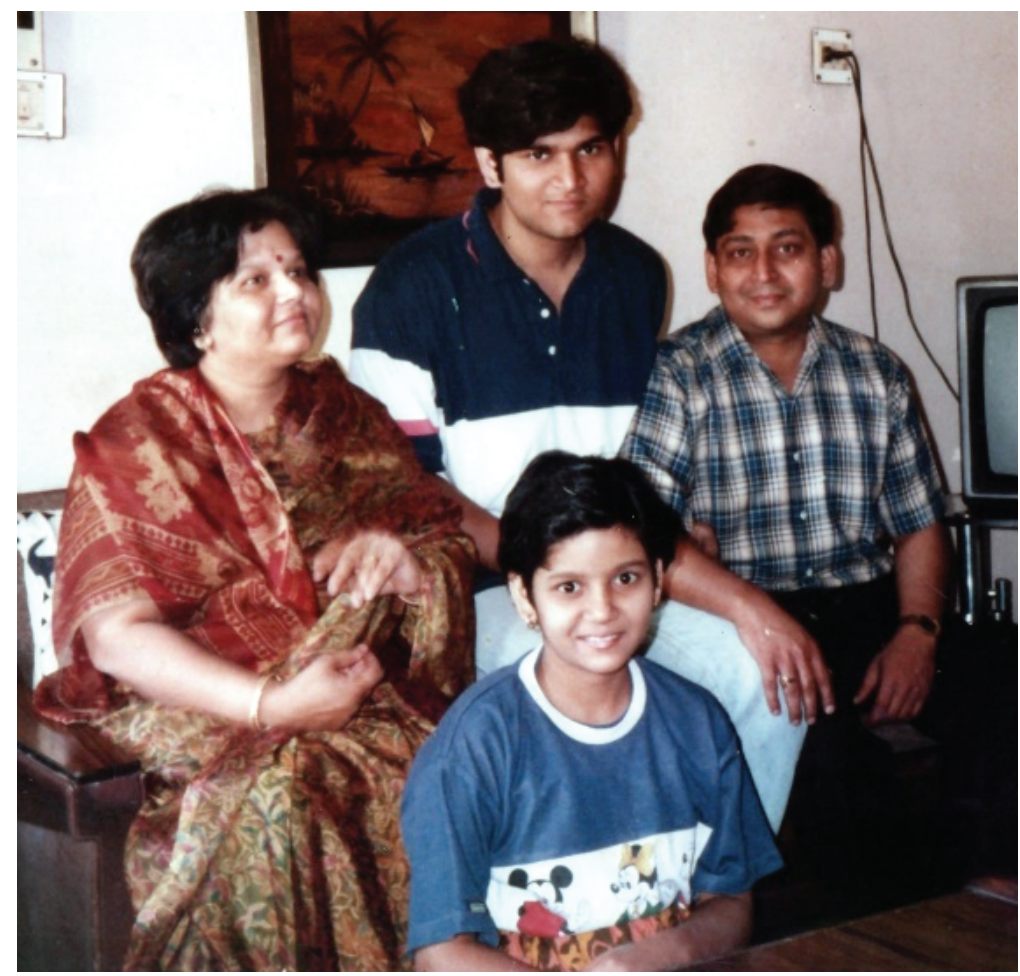

With family — growing up

During his A-levels, Vishrut suffered from debilitating neck and arm back, leading to long periods of absence from the school and an inability to put in the demanding hours of study 
required. However, he overcame this challenge with support from his family and excelled in his board exams.

\section{University Life}

Vishrut aspired to study Computer Science from IIT Kanpur as he was fascinated by computers and technology. His left brain on the other hand, wanted to complete a degree in English literature from St. Stephen's College Delhi. Life had other plans, and Vishrut was one of eight students selected from the North zone for the Singapore Airlines-Neptune Orient Lines (SIA-NOL) scholarship. It was a dream come true for him when he qualified for Computer Science at the National University of Singapore (NUS). Eventually, he graduated in Computer Science \& Information Systems with First Class Honours, and his passion for English literature and language continued lifelong through his blogs and writings.

Landing in Singapore in 1993, he forged long lasting friendships with a couple of scholars who were his family during the first year. Vishrut had a wonderful 4 years at University and wholeheartedly embraced the non-academic aspects of college life. He took great pleasure in dressing up as a geisha during a cultural fest and went on to bag a prestigious role in a prominent local play by the end of his first year. He loved to host intercultural parties where he would cook exotic Indian dishes much to the delight of his perennially hungry friends. When not occupied with cultural pursuits, he would spend all his spare time devouring books at the University libraries.

Together with another friend and a National Institute of Education (NIE) professor, he started organizing poetry-reading sessions on an old junk boat at Boat Quay. This was hugely popular with the literary community in Singapore and continued for several years. A couple of German exchange 
students introduced him to the Singapore Symphony Orchestra and at $\$ 5$ for a concert, it became one of his favourite ways to spend an evening.

Vishrut met his wife-to-be, Priya Rath, a SIA-NOL scholar as well, at the tender age of 19, during her first week in Singapore at the NUS Science canteen. They took great pride in each other's academic and professional journeys and decided early on to give back to society. Their life in Singapore was enriched by friends from all corners of the world, mutual interest in collecting Art, exploring the many nature parks in the island, and delighting in the wonderful vegetarian cuisine to be found in the most unassuming hawker stall.

\section{Ikigai - Philanthropy}

Graduating with first class honors in Intelligent Systems, Vishrut embarked on a career in consulting, financial services and digital transformation. He had made up his mind to build a career in Management Consulting, excited by the impact one could make at a relatively young age. His first job after his Master's degree was with Stern Stewart. His foundation as a deeply analytical, financial and strategy analyst was laid during those early years, guided by very able managers and mentors. In 2003, Vishrut opened the firm's Bangkok office, hired a very capable local team and soon developed a loyal client base.

He joined Marakon Associates thereafter and was soon made a partner. He continued his consulting career with Boston Consulting Group (BCG) where he really matured as a partner, honing his expertise in financial strategy and digital transformation. Following a short stint with Ernst \& Young, Vishrut decided to join his client, Siam Commercial Bank (SCB) in Bangkok. He went on to implement and scale up several important digital initiatives that enhanced customer 
experience and catapulted SCB into a digital powerhouse in Asia.

Vishrut and Priya became aware of slavery in Nepal quite by accident. During their hikes in Nepal, he and Priya usually stayed at tourist lodges where they often saw young girls working. One chilly December morning in 2008, while waiting for his flight within Nepal from Lukla (the gateway to Everest Base Camp) to Kathmandu, Vishrut and his wife saw a young girl washing clothes outside in the darkness with cold water. Their guide and friend Arjun Karki informed them that she was not a daughter of the house, but was sold by her parents to the lodge owners for 15,000 Nepalese rupee or about $\$ 130$. Hearing this, Vishrut broke down at the injustices of life, taking his wife back to the time when he was in tears after watching the movie 'Born into Brothels' about brave slum children in Kolkata.

Vishrut said in the 2014 India Se interview that over the next weeks and months attempts to 'rescue' this girl proved frustrating - her parents first didn't want her back, and then wanted a heavy monthly payment to have her back. Her 'owner' also smelled blood and demanded large payments to release his property. We realised that apart from parents, even criminals were involved. Therefore, on the advice of the local community, we decided to abandon this quest. There are better resourced organisations like Maiti Nepal that are doing a fine job here. We decided not to work with girls who were already sold, but to instead protect those who were at risk of being sold; to focus on girls from extremely poor backgrounds. Together with Arjun and his wife Sita, they set up 'Sikcha Abhiyan Nepal' or 'Kanya' with the aim to educate underprivileged girls from the Everest region - we started very small with one girl, Sabina Magar, the daughter of our porter. 
In 2009, Vishrut took a 6-month sabbatical and travelled to Najing, Solokhumbu, a remote village in the Everest. The challenge was to choose a few girls out of many, choosing the right school in the city, and building a hostel for them to stay in. Together with Arjun, Vishrut met many families, teachers and village officials and finally selected 18 girls between the ages of six and 12 to relocate to Kathmandu and complete their education. The process was not without its challenges. At one point, Vishrut was summoned to the Najing police station as someone accused him of trying to traffic the girls. It took a lot of stakeholder management and entreaties by Arjun and the girls' parents to let Vishrut off the hook.

Vishrut elaborated during his 2014 interview to India Se, The education mission was started with a seed funding of $\$ \$ 70,000$ from our personal funds to set up a hostel for girls in Kathmandu. We chose to focus on a small and closed set of girls and make a much higher per capita investment in healthcare, nutrition, education and extracurricular activities. Our annual expenditure per girl is about $\$ \$ 2000$.... Many of the girls were malnourished, stunted or had lice or stomach-worm infestation when they joined us. Through patient nursing over the years, they are now mostly in their expected quartile for weight and height. We focus on holistic development - all the girls attend an hour of Taekwondo every morning, and an hour of classical/ folk singing or dancing every evening. Their achievements include 13 medals in the last national level Taekwondo competition, televised dance performance for National Day celebration and becoming cultural ambassadors to Japan and India. As of 2019, the eighteen girls in the program are now confident and mature young women, doing well in academics, music, dance and taekwondo. All the girls were Vishruth's pride and joy and he never tired of speaking about their accomplishments. 


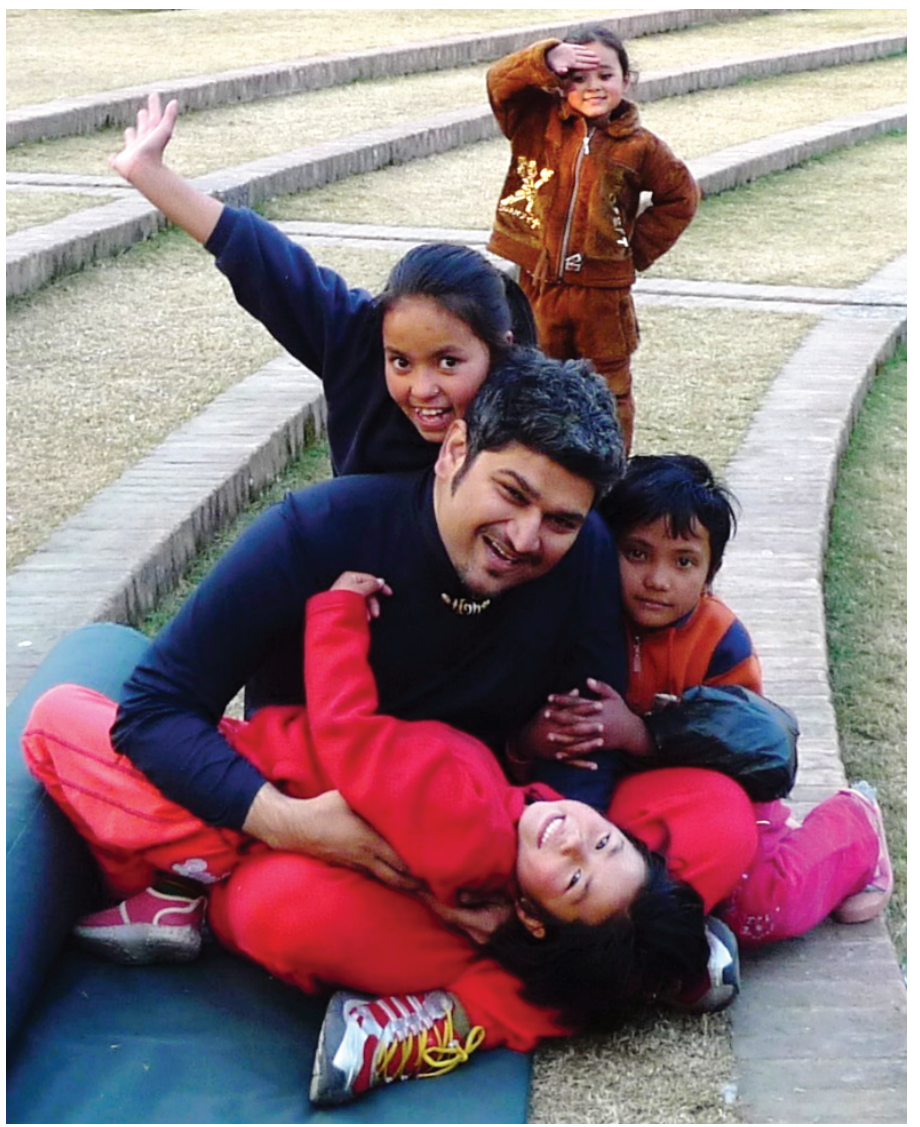

With the grils he adopted

Vishrut also worked with a professor from INSEAD, Singapore to help establish 'Aidha', an organization to upskill and empower foreign domestic workers in Singapore.

\section{Vishrut - The Person}

Vishrut was a renaissance man. He believed in living life to the fullest and pursuing all passions as one never knows when one's time will be up. He was the life of any party thanks to his keen intellect and wide raging opinions from something as 


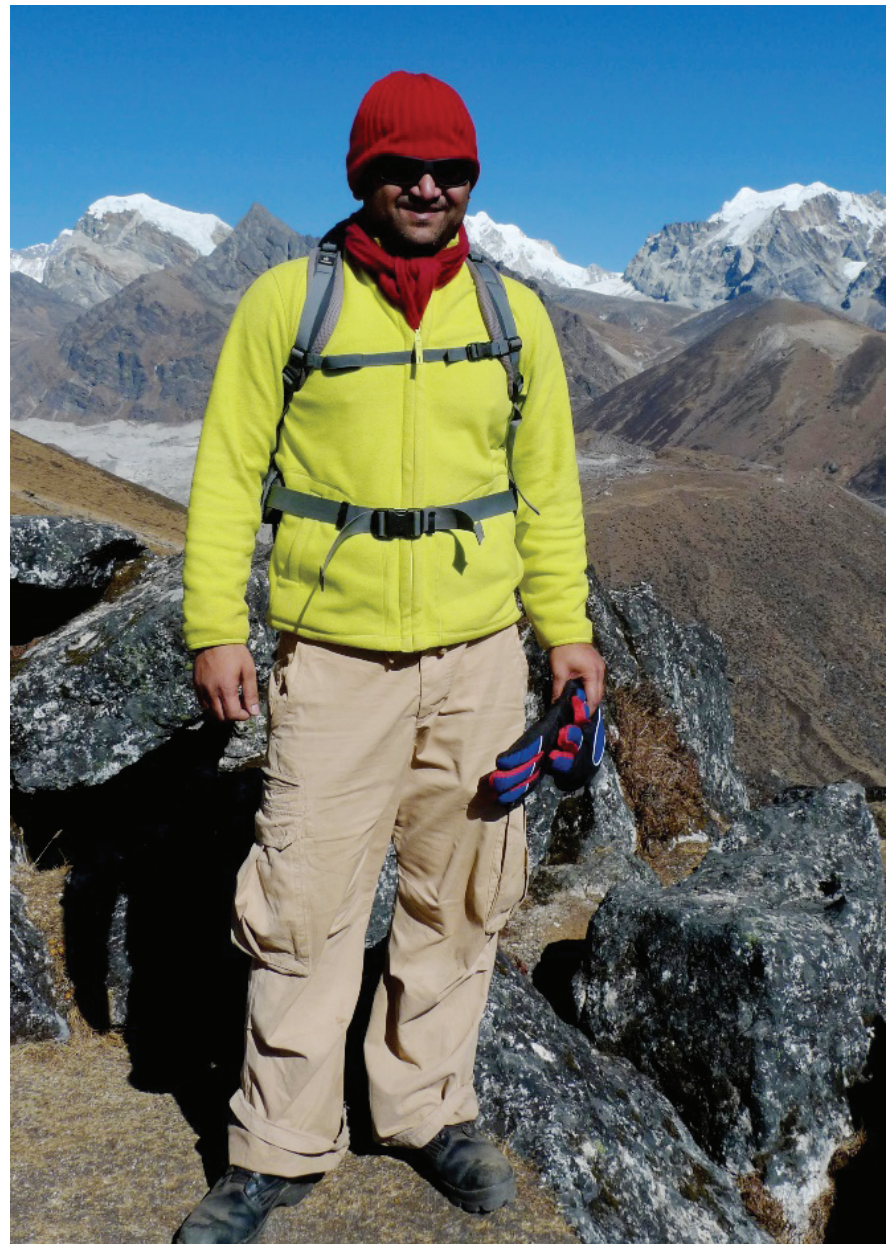

Trekking in the mountains

mundane as the knot count on his bedspread to the latest advances in Artificial Intelligence. A science fiction buff, his favorite scenario and most hotly-debated topic was for all humanity to exist in the Cloud in the not so distant future. Determination to do well in anything he started, confidence, reading widely and standing for one's opinion were some of his key qualities. He had genuine care for his colleagues and juniors. He led by example, worked as hard as his team, and built many successful careers in Singapore and Thailand. 
He was generous with his time, sharing his knowledge and passions with all. He had appreciation of the fine things in life (such as clothes, shoes, and perfume) but did not lose the ability to relish the basics (e.g. wooden huts with outdoor toilets and no heating in the Himalayan trails).

He loved singing and could imitate the voices of top Indian singers such as Kishore Kumar and Rafi. A typical evening at home would start with him lighting exquisitely fragranced incense sourced from a Greek monastery, decanting a bottle of red wine, putting on his Qawwali or Jazz playlist, re-arranging the ikebana for the nth time and adding finishing touches to his culinary creations.

Vishrut was passionate about fine interiors and he lovingly remodelled four of his homes in Singapore over the span of 12 years. Two homes were featured in top interior design publications in Singapore and India. He took great joy in the acquisition process, travelling to a remote village in Ubud, Bali, Indonesia to source the perfect tamarind wood block for his dining table, or to a nursery in Malaysia for the most sculptural frangipani trees for his garden.

Vishrut's latest hobbies were Chinese antiques and porcelain, perfume-making and ikebana. He ran a Facebook group 'Asian Style + Interiors + Antiques' dedicated to Asian style and interiors for more than one thousand collectors and aficionados.

Vishrut was liberal and egalitarian to the core, shunning divisive ideologies and people. He never hesitated to speak uncomfortable truths to defend his values. He had great respect for those who had made it from humble beginnings. A staunch feminist, he always encouraged his wife and his female team members to realize their potential. He believed 
passionately in an egalitarian society that did not hold back its women and other minorities.

His bond with his wife deepened with their yearly sojourns to Nepal starting in 2007. Little did they know that their first

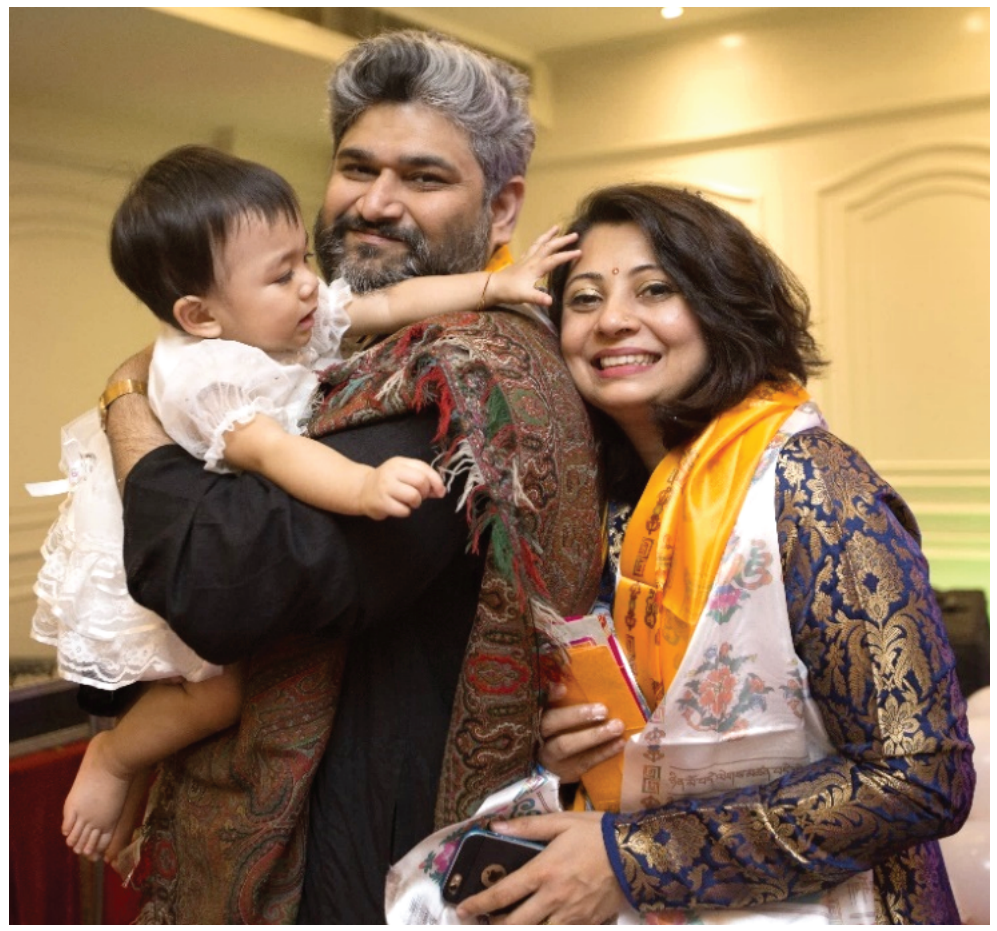

With family

hike on the Annapurna trail would lead to a lifelong love of the Himalayas and the establishment of the charity Kanya! Their diametrically different cultures (Uttar Pradesh and Orissa) allowed them to immerse themselves in each other's families, customs, and cuisines. His wife was deeply touched when Vishrut decided to travel to Orissa all on his own to meet her family and experience Oriya culture a year or so after they began dating. 
Parenthood came at age forty and Tashi became the love of his life. No matter how tired he was at the end of a long day at work, he would never refuse Tashi if she wanted to admire the moon in their neighbourhood park.

Vishrut's professors at NUS, Chris Marshall and C.J. Meadows had a deep impact on him as did Jens Lottne, his manager at BCG \& SCB. Chef Gaggan Anand, a close friend in Bangkok, taught Vishrut about innovation \& working with diverse teams. From Arjun Karki, he learnt about overcoming adversity and establishing a successful business.

Happiness for him meant giving back to society, spending time with family and friends, enjoying downtime at home with a glass of wine and his books, and developing quality relationships at work and outside of work. A very gregarious personality, he always had a smile on his face and filled up any room with his booming laugh.

His greatest success, in his own words, was Kanya, the life he built in Singapore, and the strong family ties and friendships he enjoyed. Vishrut would have loved to see all his 18 girls graduate from college and settle down in life. This will now be completed by his wife Priya, and his family and friends, as destiny had other plans. Vishrut Jain passed away on 4th February 2019 due to a sudden cardiac arrest in Nepal. 